\title{
Reduction of Nanoparticle Load in Cells by Mitosis but Not Exocytosis
}

\author{
Joël Bourquin, ${ }^{\dagger}$ Dedy Septiadi, ${ }^{\dagger}$ Diఠ Dimitri Vanhecke, ${ }^{\dagger}$ Sandor Balog, ${ }^{\dagger}{ }^{\dagger}$ Lukas Steinmetz, ${ }^{\dagger}$ \\ Miguel Spuch-Calvar, ${ }^{\dagger}$ Patricia Taladriz-Blanco, ${ }^{\dagger}$ Alke Petri-Fink, ${ }^{,}, \ddagger$ \\ and Barbara Rothen-Rutishauser* ${ }^{*} \dagger$ (i) \\ ${ }^{\dagger}$ Adolphe Merkle Institute, University of Fribourg, Chemin des Verdiers 4, 1700 Fribourg, Switzerland
${ }^{\ddagger}$ Department of Chemistry, University of Fribourg, Chemin du Musée 9, 1700 Fribourg, Switzerland
}

Supporting Information

\begin{abstract}
The long-term fate of biomedically relevant nanoparticles (NPs) at the single cell level after uptake is not fully understood yet. We report that lysosomal exocytosis of NPs is not a mechanism to reduce the particle load. Biopersistent NPs such as nonporous silica and gold remain in cells for a prolonged time. The only reduction of the intracellular NP number is observed via cell division, e.g., mitosis. Additionally, NP distribution after cell division is observed to be asymmetrical, likely due to the inhomogeneous location and distribution of the NP-loaded intracellular vesicles in the mother cells. These findings are important for biomedical and hazard studies as the

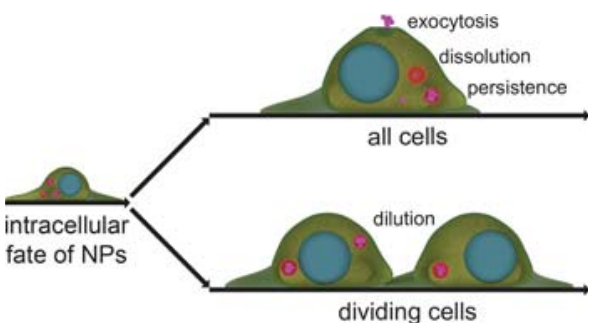
NP load per cell can vary significantly. Furthermore, we highlight the possibility of biopersistent NP accumulation over time within the mononuclear phagocyte system.
\end{abstract}

KEYWORDS: engineered nanoparticles, intracellular fate, exocytosis, mitosis, live cell imaging

$\mathrm{E}$ ngineered nanoparticles (NPs) such as gold (Au NPs), silica $\left(\mathrm{SiO}_{2} \mathrm{NPs}\right)$, or super paramagnetic iron oxide $\mathrm{NPs}$ (SPIONs) are already in use for various medical applications including imaging and cancer irradiation therapy and as carriers for drug delivery. ${ }^{1,2}$ Such NPs can be administered into the bloodstream by injection, ingestion, or inhalation and transported to targeted sites. However, the fate of these NPs after delivery to targeted sites, i.e., cells and tissues, is not fully understood. ${ }^{1}$ The potential clearing from the body depends on the physicochemical properties of the NPs and is managed through physical filtration (e.g., renal clearance) or transcytosis (e.g., hepatic clearance), in which the NPs are consecutively excreted in either urine, bile, or feces. ${ }^{1,3}$ Another clearance pathway is performed by the mononuclear phagocyte system (MPS), which consists mainly of monocytes and macrophages that retain and degrade the uptaken NPs in the lysosomes. ${ }^{4-9}$ Biodistribution, organ-based clearance, and cellular endocytic uptake pathways of NPs are extensively studied, whereas the intracellular fate and the potential clearance of NPs at the cellular level receives much less attention. ${ }^{10-12}$

Biopersistent or nonbiodegradable materials pose the risk of potentially accumulating within cells, as lysosomes are often understood as the end point in intracellular trafficking. ${ }^{6,13}$ Various in vivo studies have reported the long-term retention (e.g., weeks to month) of such biopersistent NPs (e.g., Au NPs or nonporous $\mathrm{SiO}_{2} \mathrm{NPs}$ ) in the MPS, especially in the liver. ${ }^{1,14,15}$ Even months after a single intravenous injection of Au NPs, substantial Au NP numbers were still found in lysosomes in
Murine Kupffer cells, despite the absence of any pathomorphological response. ${ }^{14,16,17}$

The lysosomal exocytotic pathway has been suggested as a possible pathway for the prevention intracellular accumulation of foreign material. ${ }^{8,18-20}$ The classical stimulus of lysosomal exocytosis is a $\mathrm{Ca}^{2+}$ influx into the cell, an indicator of cell membrane rupture. ${ }^{20-22}$ It has been proposed that lysosomes can fuse with the cell membrane to release undigested material. ${ }^{8}$ Exocytosis of NPs has been investigated using differently sized and surface-functionalized particle models, but a consensus about which physicochemical properties (e.g., size, surface charge, or surface functionalization) affect the efficiency of NP exocytosis the most has yet to be found. ${ }^{11,23,24}$ Even though the mechanism of NP exocytosis is under debate, it is clear that the cell type plays a major effect on the exocytosis pattern of NPs. ${ }^{18}$

In addition to NP degradation and exocytosis, cell division (or mitosis) can also contribute to reduction of intracellular NP concentration. ${ }^{25,26}$ By undergoing mitosis, cells are dividing their intracellular contents (including possible NP-laden lysosomes) and, therefore, the NP load is expected to be shared among the daughter cells. ${ }^{27}$ This distribution of NPs could modulate the efficiency of NP-based drugs targeting dividing cells (e.g., cancer or stem cells). The limited data available suggest an unregulated distribution process similar to the 
distribution of lysosomes during mitosis. ${ }^{28}$ Interestingly, an asymmetric NP distribution is often observed: one daughter cell receives more NPs than the other. ${ }^{26,27}$ It has been speculated that this process may help cells to prevent the spreading of undigested materials into the whole population by concentrating them in few individual cells. ${ }^{29}$

Herein, we investigate the in vitro fate of three different types of NPs: nonporous fluorescently labeled $71 \mathrm{~nm} \mathrm{SiO} 2 \mathrm{NPs}$ and polyvinylpyrrolidone (PVP)-coated Au NPs (Au@PVP; 20 and $46 \mathrm{~nm}$ in size) in primary monocyte-derived macrophages (MDMs), macrophage cell line (J774A.1), and a nonphagocytic cell line (HeLa).

Our hypothesis is that NPs can be exocytosed from lysosomes, while other effects (e.g., mitosis) are running concomitant. ${ }^{18,25}$

Our results show that dilution of NPs in cell division plays a dominant role in cellular NP distribution, while in contrast to some reports in literature, no significant amount of NP exocytosis was detected over a time period of up to $48 \mathrm{~h}$ postexposure. This was shown to be independent of the NP size and material in macrophages. ${ }^{30}$

\section{RESULTS AND DISCUSSION}

Synthesis and Characterization of the Model NPs. Our study focused on two biocompatible NPs systems: Au NPs and nonporous $\mathrm{SiO}_{2} \mathrm{NPs}$.

Au NPs have been shown to be relatively biologically inert and nonbiodegradable and are therefore thought to have great potential as a base for biomedical NPs. Many different studies investigated the interaction of such engineered Au NPs with biological systems in vitro and in vivo. Au NPs of various sizes have been shown to be secreted in different cell lines by previous studies. ${ }^{11,23,31}$ Furthermore, they offer the possibility of being surface-functionalized (e.g., with PVP), which can improve their stability in cellular environments. Moreover, there are sensitive quantification techniques (e.g., ion-coupled plasma optical emission spectroscopy (ICP-OES)) available to detect the particles in such complex samples. Herein, the Au NPs were functionalized with PVP to increase NP stability in serumcontaining cell culture medium (cCCM). ${ }^{32}$ PVP-coated NPs have been shown to be readily uptaken by cells with no acute toxic effects. ${ }^{33}$ The colloidal stability of the Au NPs in cCCM was tested by $\mathrm{UV}-$ vis spectroscopy after 0 and $24 \mathrm{~h}$ and revealed no aggregation in CCCM for either particle size (Figure S1).

Silica as a base material is also used in biomedical particles. Mesoporous silica NPs (MSN) are generally used for biomedical applications. They offer high loading capacity of active ingredients enabling their potential use in bioimaging, drug delivery and photodynamic therapy. ${ }^{34-37}$ However, studies have shown that such MSN can be degraded in relatively short times in biological environments. ${ }^{38-40}$ Since this biodegradability was not optimal for our research goals, as it would increase complexity in the detection and sample analysis, we chose to use nonporous particles. While they are less frequently used for biomedical applications, nonporous silica particles are more stable and show less degradation in the time frame we were interested in (i.e., 1 week). ${ }^{35,38,41,42}$ Furthermore, different nonporous silica particle sizes $(25,45$, and $75 \mathrm{~nm})$ have been shown to be secreted by different cells (HUVEC, C17.2 cells and PC12 cells) in a previous study. ${ }^{43}$ The nonporous $\mathrm{SiO}_{2} \mathrm{NPs}$ were further functionalized with the fluorescent dye rhodamine $\mathrm{B}(\mathrm{RhoB})$ in the silica matrix to ease their detection within cells using confocal laser scanning microscope (cLSM) and fluorescence-assisted flow cytometry (FC). The stability of the
$\mathrm{SiO}_{2} \mathrm{NPs}$ in cCCM was confirmed using CryoTEM (Figure S1A). We could observe the onset of moderate aggregation only when the particle concentration was increased more than 10 times (from 20 to $250 \mu \mathrm{g} / \mathrm{mL}$ ).

Representative TEM micrographs of the individual particles are depicted in Figure 1A, and the summary of the characterization is depicted in the table in Figure $1 \mathrm{~B}$.

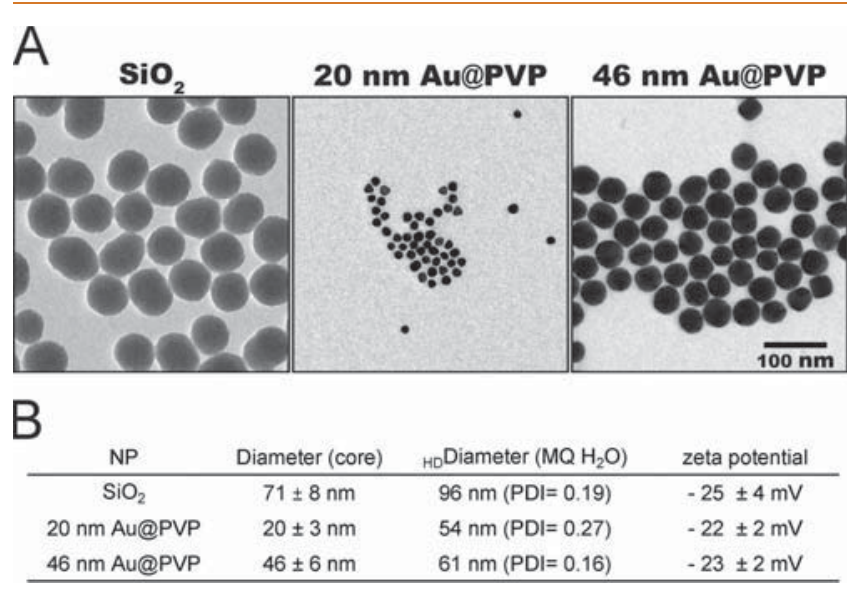

Figure 1. Characterization of the different NPs. (A) Representative TEM images of different NPs. Scale bar $=100 \mathrm{~nm}$. (B) Table recapitulating the most important physicochemical characteristics of NPs including core size, hydrodynamic diameter (in Milli-Q (MQ) $\mathrm{H}_{2} \mathrm{O}$ ), and $\zeta$ potential (in $0.1 \times$ phosphate-buffered saline $(\mathrm{PBS})) . \mathrm{HD}=$ hydrodynamic; $\mathrm{PDI}=$ polydispersity index.

Particles Are Taken up and Retained by All Tested Cells. Commonly, NP cellular exocytosis was studied by a NP loading step in the range of minutes to a few hours (often $6 \mathrm{~h}$ ) followed by observing the release of NPs from the cells into the extracellular space in the following minutes to hours. ${ }^{18,23,24,44-53}$ The highest concentrations of exocytosed NPs were usually reported within the first few hours. However, after $6 \mathrm{~h}$, the uptaken NPs might still reside in sorting or early endosomes, where membrane recycling occurs that can also resecrete the NPs to the extracellular space. The endosomal trafficking depends on the ingested materials. Some materials (e.g., cell debris) can reach lysosomes within $30 \mathrm{~min}$, while others (i.e., latex particles) have been shown to only reach the lysosomes hours later. $47,50,54-57$

As the required time to fully process the endocytic vesicles varies depending on the uptaken cargo, the incubation time of 24 $\mathrm{h}$ was selected to ensure the NPs reached the lysosomes, and therefore, recycling processes were excluded. ${ }^{6}$

Macrophages were chosen as the primary cell model as they are the main cell type represented in the MPS taking up administered NPs. ${ }^{13}$ J774A. 1 mouse macrophages are a cell line often used to assess NP-cell interaction. ${ }^{58-61}$ Another cell type, human primary monocyte-derived macrophages (MDMs), are used as they are supposed to be more human relevant in addition to the fact that mitosis is absent in MDMs. Finally, the HeLa cell line was included as literature on NP exocytosis is available. ${ }^{30,62}$

Initially, the biocompatibility of the three NPs was evaluated by two different cytotoxicity assays. The lactate dehydrogenase (LDH) assay showed no increase in membrane permeabilization after NP administration, indicating no acute toxic effects. This result is confirmed by the resazurin assay: the intracellular metabolic activity of resazurin to resarufin turnover was not 


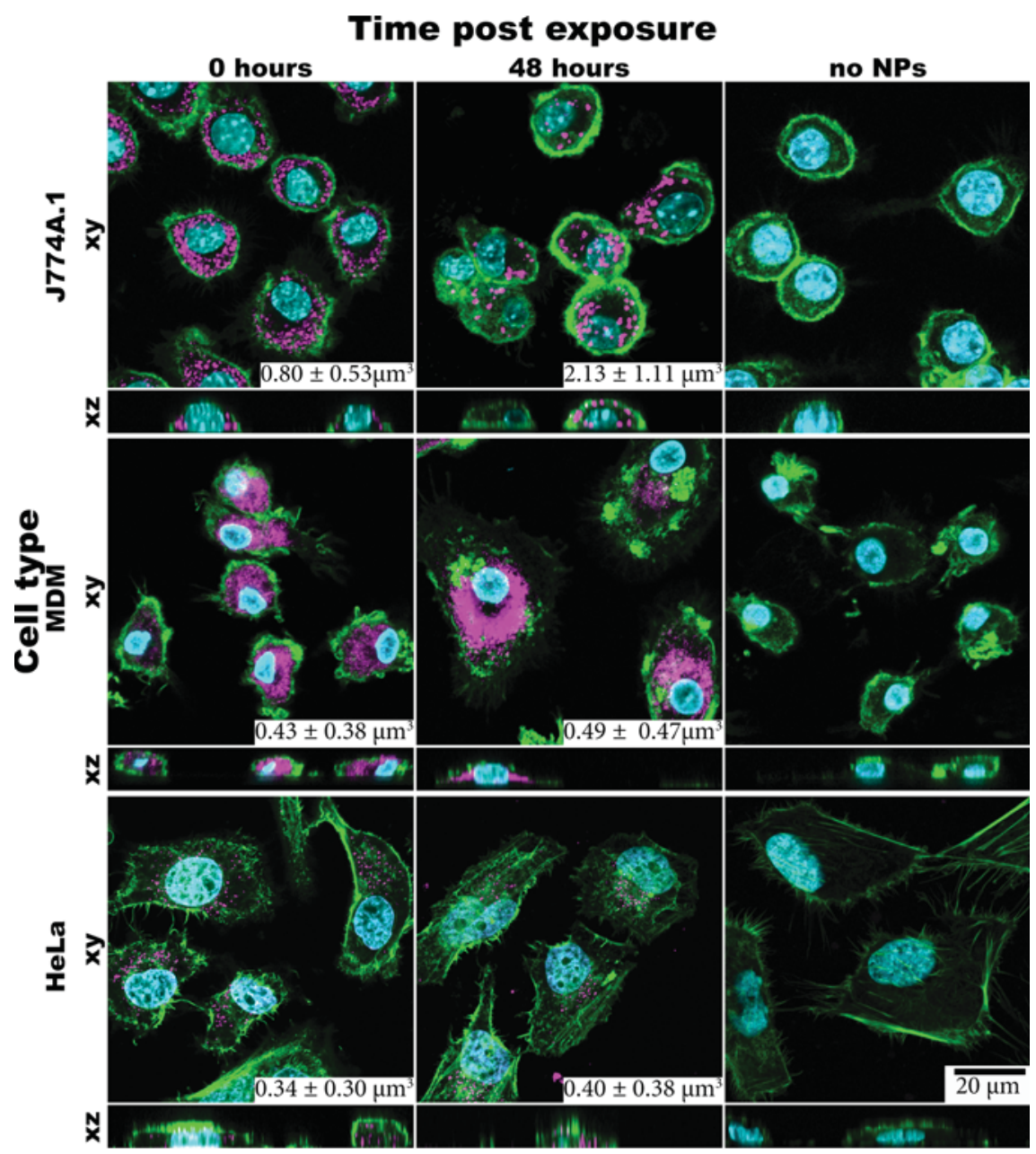

Figure 2. Confocal laser scanning microscopy confirms uptake and retention of $\mathrm{SiO}_{2} \mathrm{NPs}$. Single-plane visualization of $\mathrm{SiO}_{2} \mathrm{NPs}_{\mathrm{in}}$ the different cell types was accomplished by confocal laser scanning imaging. After exposure to NPs, the cells were washed and immediately fixed and stained $(0 \mathrm{~h})$ or further incubated for $48 \mathrm{~h}$ in NP-free medium $(48 \mathrm{~h})$ before the fixation and staining. The NPs (magenta) are localized inside the cells, and still detectable signals could be seen in both time points, but not the negative control. F-Actin was stained as cellular marker using a Phalloidin AlexaFluor 488 conjugate (green), and the nucleus was stained using 4',6-diamidino-2-phenylindole (DAPI) (cyan). The $x z$ projection in the bottom shows the NPs are localized intracellularly. The volume (mean \pm standard deviation) of NLVs is denoted in the white insert at bottom right of the images. Scale bar $=20 \mu \mathrm{m}$.

impaired for any of the tested particles at working concentrations of $20 \mu \mathrm{g} \mathrm{mL}^{-1}$. (Figure S2)

cLSM z-stack images were acquired to confirm the uptake and retention of the fluorescently labeled $\mathrm{SiO}_{2} \mathrm{NPs}$ (Figure 2) at 0 and $48 \mathrm{~h}$ post-exposure. It could be shown that the cells were filled with particles directly after exposure and at $48 \mathrm{~h}$ postexposure, but a lower signal was registered in HeLa cells in comparison to the two macrophages cell types in both time points. Moreover, an increase in NP-loaded vesicles (NLVs) volume $48 \mathrm{~h}$ post-exposure was observed by comparing the mean volumes of the NP signal of at least 438 individual vesicles. Our analysis shows a statistically significant result (with $p$ value of J774A.1 and MDM: < 0.0001; HeLa: 0.0035) proving the increase of the vesicle's volume in all cell types after $48 \mathrm{~h}$ postexposure (mean and standard deviations are reported in the inset of Figure 2). We argue that this size increase is likely due to fusion events of NLVs with lysosomes, indicating that even after $24 \mathrm{~h}$ of uptake the endosomal maturation and trafficking may not yet be fully complete.

Additionally, the NP trafficking to the lysosomes was monitored in a colocalization experiment. After $24 \mathrm{~h}$ of exposure, the location of the NPs in the cells was assessed and compared to a lysosomal staining. The Pearson's correlation coefficients (PCC) of the colocalizations between $\mathrm{SiO}_{2} \mathrm{NPs}$ and the lysosomal marker were $0.72,0.72$, and 0.65 for J774A.1, MDMs, and HeLa, respectively, indicating a high (but not complete) degree of colocalization after $24 \mathrm{~h}$ (Figure S3).

The uptake and retention of both types of the Au NPs was confirmed using dark field (DF) microscopy since no fluorescent marker was attached to the Au NPs (Figure 3). The electron-dense and highly scattering Au NPs appear as bright spots within the cells (cell outline is shown as thin white line). Both Au NP types appear intracellularly in all cell types for both tested time points. No visual differences could be observed between the bright white spots, which are expected to be NLVs, for the two different particle sizes. Our semiquantitative image analysis data shows that the bright spots are slightly larger in area $48 \mathrm{~h}$ post-exposure than without post-exposure in all conditions. Significant increases (student's $t$ test) were observed in both Au NP sizes in J774A.1 and the $20 \mathrm{~nm} \mathrm{Au@PVP} \mathrm{in} \mathrm{the} \mathrm{case} \mathrm{of}$ MDMs (Figure S4). 

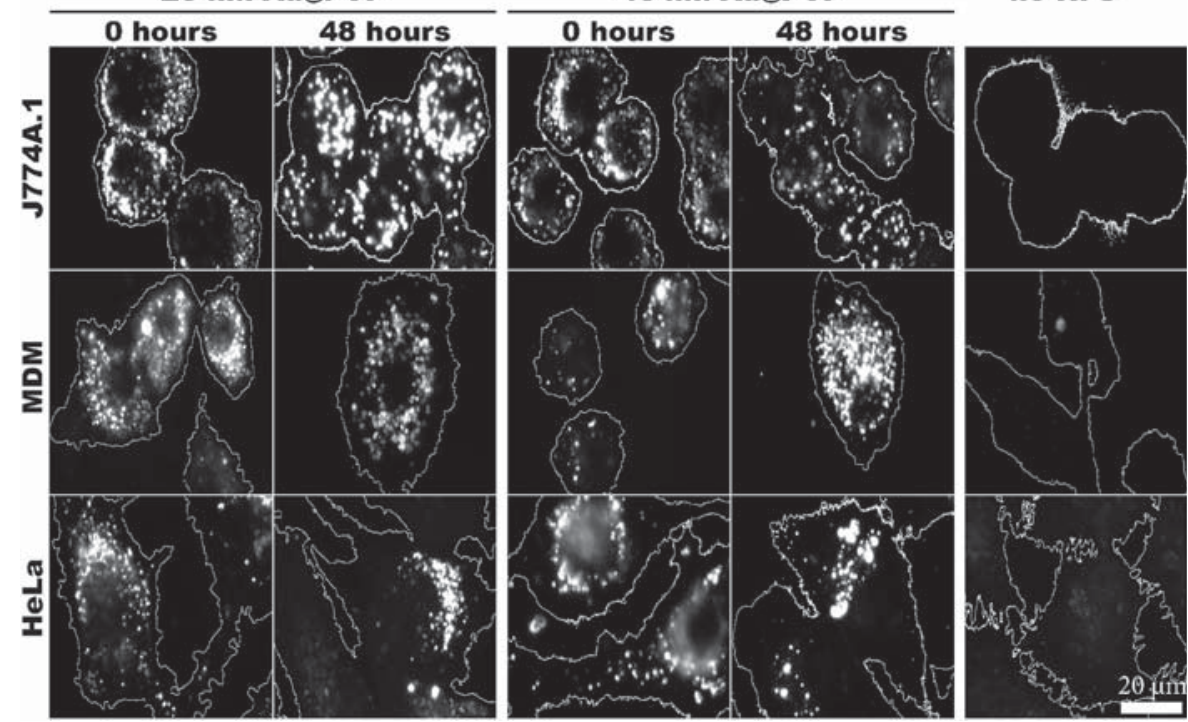

Figure 3. DF microscopy revealing the uptake of Au NPs in all cell types. DF microscopy confirms the uptake of both types of Au NPs within the different cell types and the presence of NPs 0 and $48 \mathrm{~h}$ post-exposure. Each cell type shows intracellular bright white spots originating from the scattering of the Au NPs. The white line marks the outline of the cells. Scale bar $=20 \mu \mathrm{m}$.

Flow Cytometry Shows No Decrease of Fluorescence in Nondividing Cells. To quantify the intracellular amount of $\mathrm{SiO}_{2} \mathrm{NPs}$ over time, FC was applied. The fluorescence signal from the particles in or adhered to the cells was analyzed at 0,24 , or $48 \mathrm{~h}$ post-exposure in NP-free cCCM. Over the analyzed time period, the fluorescent signal associated with $\mathrm{SiO}_{2} \mathrm{NPs}$ inside the MDM cells was stable and did not show any significant reduction (Figure 4A, blue line) of the mean fluorescence intensity (MFI; $p$ value 0.944 , nonparametric, Friedman test). In contrast, the cell lines J774A.1 (Figure 4A red line) and HeLa (Figure 4A, green line) showed a significant decrease in MFI after $48 \mathrm{~h}$ post-exposure: the MFI dropped to below $50 \%$ of the initial value directly after exposure $(0 \mathrm{~h})$ resulting in $p$ values of 0.041 and 0.028 for J774A. 1 and HeLa, respectively.

This signal decrease could be explained by (i) fluorescence quenching or NP degradation in the lysosomes, (ii) exocytosis or (iii) NP dilution due to mitosis.

The effect of the lysosomal environment on the fluorescence was assessed through incubation in artificial lysosomal fluid (ALF). ${ }^{42,63}$ No significant reduction of fluorescence intensity was observed after $48 \mathrm{~h}$ in ALF (Figure S5), in accordance with the work of Milosevic et al. ${ }^{41}$ This comes to no surprise as the fluorescent dye is incorporated in the matrix and is not readily exposed to the acidic fluid. ${ }^{42}$

To determine whether the decrease in fluorescence was the result of exocytosis, we introduced the ionophore ionomycin, which increases intracellular $\mathrm{Ca}^{2+}$ concentrations and can thus stimulate lysosomal excretion leading to increased NP exocytosis in various cell types. ${ }^{18,64}$ The efficiency of ionomycin to stimulate lysosomal exocytosis has been tested in the case of MDMs using a $\beta$-hexosaminidase assay which showed that the release of the lysosomal enzyme was significantly increased upon incubation of the cells with ionomycin (Figure S6). After $24 \mathrm{~h}$ of exposure to the $\mathrm{SiO}_{2} \mathrm{NPs}$, the cells were incubated with $20 \mu \mathrm{M}$ ionomycin for $6 \mathrm{~h}$ and further analyzed using FC. Neither of the three cells types showed significant changes in their MFI compared to the untreated control (i.e., no ionomycin) according to a student's $t$ test (Figure 4B), indicating that lysosomal exocytosis had no significant effect on NP release in all tested cell types.

The ionomycin experiment was performed only for an early time to minimize the effect of dilution of NPs by cell division (and because of ionomycin's long-term apoptosis inducing effects). Since even ionomycin-forced $\mathrm{Ca}^{2+}$ influx could not reduce the MFI per cell significantly, in neither the macrophages nor the HeLa, we conclude that lysosomal exocytosis of NPs in the herein-investigated cells and NP model is of minor importance.

One explanation for why we do not observe any significant reduction in fluorescence even after stimulation of exocytosis by ionomycin could be the endosomal maturation process which decides the final fate of an engulfed cargo. After NP uptake, the particles end up in endocytic vesicles. From there, the early endosomes mature into late endosomes which then fuse with each other to form larger structures and combine with preexisting lysosomes to form so-called endolysosomes. Finally, by fusion of endolysosomes with phagosomes, the so-called phagolysosomes are formed with a specialized acidic and hydrolytic milieu. ${ }^{65}$ It has been shown that only a minor fraction of the uptaken cargo can be excreted again into the extracellular space via slow/fast recycling endosomes and thus bypass the possible lysosomal degradation. ${ }^{66}$ During this process, the vesicles are constantly trafficked toward the perinuclear space, increasing the distance to the cellular membrane and reducing the probability of fusing with it. ${ }^{67}$ This means that there is a possibility of NP release in endosomes, but NP release becomes less probable after trafficking into lysosomes or phagolysosomes.

We therefore speculated that the decrease of fluorescence could be due to dilution of the NPs in increasing cell numbers during cell division rather than being the result of exocytosis. This would explain the difference between the dividing (J774A.1 and $\mathrm{HeLa}$ ) and nondividing (MDM) cells in the reduction of the MFI with increasing time post-exposure (see Figure 4A). To test this hypothesis, we repeated the experiment under serumdeprived conditions (i.e., $0.5 \%$ instead of $10 \%$ FBS) to inhibit the cell proliferation (Figure S7). As expected, inhibiting the cell proliferation resulted in an almost constant MFI and a drop of 
A

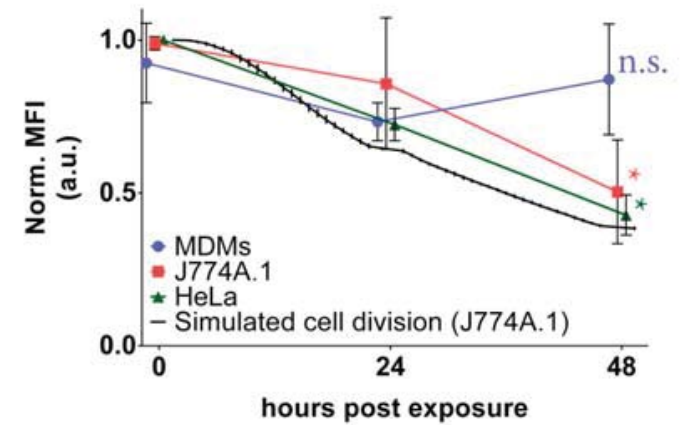

B

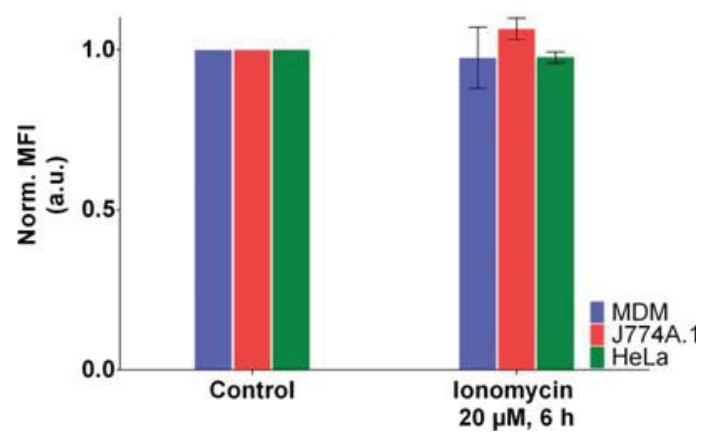

Figure 4. Flow cytometry to analyze cell-associated fluorescence. (A) Reduction of mean fluorescence intensity (MFI) 0, 24, and $48 \mathrm{~h}$ post-exposure. The fluorescence decreases significantly for the two cell lines (J774A.1 in red and HeLa in green; $p$ values 0.042 and 0.028, respectively), while the MFI of the MDM in blue remains constant ( $p$ value 0.944$)$. The graph shows the mean of three individual experiments \pm standard deviation (SD). Black line simulates the MFI expected from dilution due to cell division. n.s. = nonsignificant. (B) Effects of the lysosomal exocytosis stimulated by ionomycin on the MFI after $6 \mathrm{~h}$ of treatment. No significant reduction (i.e., $p$ value of paired $t$ test $>0.05$ ) was detected for any of the tested cells. The graph depicts the MFI \pm SD of three individual experiments normalized to the untreated control.

only $10 \%$ compared to the initial value that was observed. This reduction can be explained by either the presence of a few cells that still proliferated or stress-induced release of microvesicles containing particles, as previously observed by other studies in starvation conditions. ${ }^{68}$ We cannot exclude that cell functions such as exocytosis were affected in this experiment.

Additionally, we simulated the MFI of a population of macrophages undergoing cell division. Proliferation of J774A.1 macrophage cells in the presence of $\mathrm{SiO}_{2} \mathrm{NPs}$ was experimentally obtained by counting the cell number at specific time points. Doubling time was found to be $26.9 \mathrm{~h}$ (three independent repetitions; mean over $96 \mathrm{~h}$ ). We then created an R (version 3.4.4) simulation (see SI S8 for the code) in which this parameter was used. The simulation assumes a healthy cell culture and registers the fluorescence intensity of each cell in a culture at each time point. Mitosis occurred when the doubling time was reached, and the two daughter cells each received $51.6 \%$ (as experimentally found as shown in Figure 6C) of the mother's fluorescence signal. The simulation ran 25 times, always starting with a seed of 1000 mother cells, with each at a random time point in its cell cycle. Each experiment was run to simulate a cell cycle period of $48 \mathrm{~h}$. The results of the simulated MFI are shown in Figure 4A (black line).

The results of the simulation are in very good agreement with the experimental data, with the decrease in MFI being only slightly faster in the simulation than in the experiments. This difference can be accounted for by considering that the simulation does not incorporate the effects of environmental factors such as space availability (cells in confluent cultures will divide slower), reduced serum availability in later time points, or a slower start of growth just after seeding as has been reported. ${ }^{69}$ We hypothesize a gradual dilution of the NPs within increasing culture time which could finally result in cells without NPs and spreading of few NPs over many cell.

No Exocytosis of Au NPs in Macrophages. As exocytosis of $\mathrm{Au} \mathrm{NPs}$ has been described to be size dependent, we investigated the exocytosis of two different Au@PVP NP sizes (20 and $46 \mathrm{~nm}$ mean core diameter) using a complementary quantification method: ICP-OES. ${ }^{23}$ All three cell types were exposed for $24 \mathrm{~h}$ with NPs and either directly analyzed $(0 \mathrm{~h})$ or incubated for another $48 \mathrm{~h}$ with NP-free cCCM. The extracellular fraction and the cell lysates were digested, and their gold content assessed.

The intracellular fraction (light gray) and the extracellular fraction (dark gray) are plotted for both Au NP sizes in Figure 5.

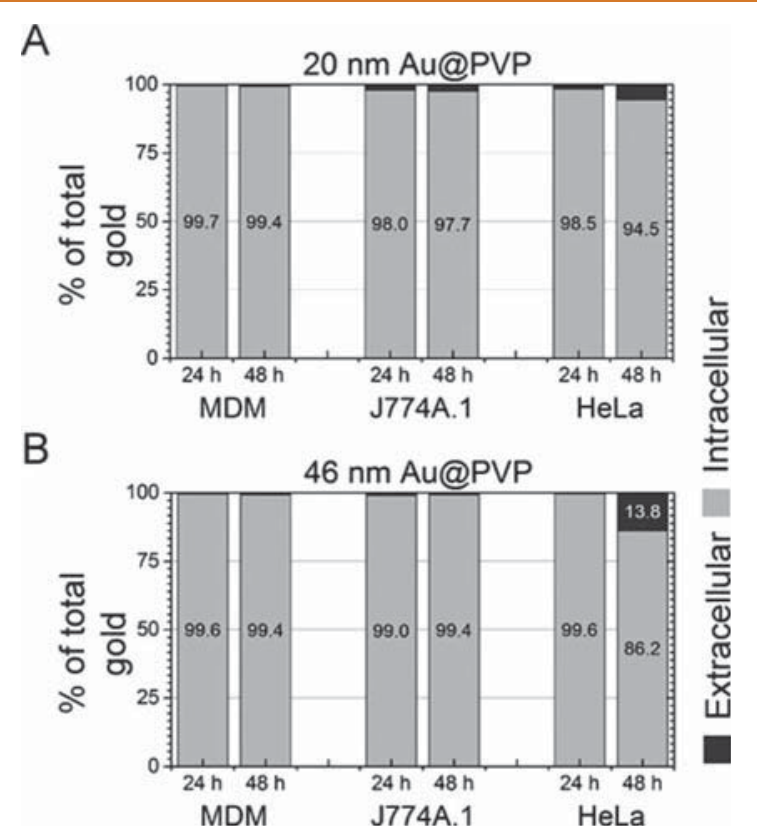

Figure 5. ICP-OES analysis of the gold content of cells show no reduction over time for macrophages. Distribution of the location of 20 nm Au@PVP NPs (A) and 46 nm Au@PVP NPs (B) after 24 and $48 \mathrm{~h}$ post exposure, respectively. Almost the entire amount of gold was found in the intracellular fraction (light gray) for the macrophages. Only the $46 \mathrm{~nm}$ Au@PVP NPs (B) showed a substantial amount of gold in the supernatant (dark gray) in HeLa cells $48 \mathrm{~h}$ post exposure.

The extracellular fraction of the macrophage cell types (MDMs and J774A.1) contained only a very small amount of gold (e.g., $<2 \%$ of total detected gold), below the limit of quantification, an observation independent for NP size and time post-exposure. The limit of detection with ICP-OES is in the range of $17 \mathrm{ng}$ $\mathrm{mL}^{-1}$ for gold corresponding to a very low fraction, i.e., $1 \%$ gold in the supernatants. Since we are at the detection limit of the instrument we can, however, not exclude that a low number of 


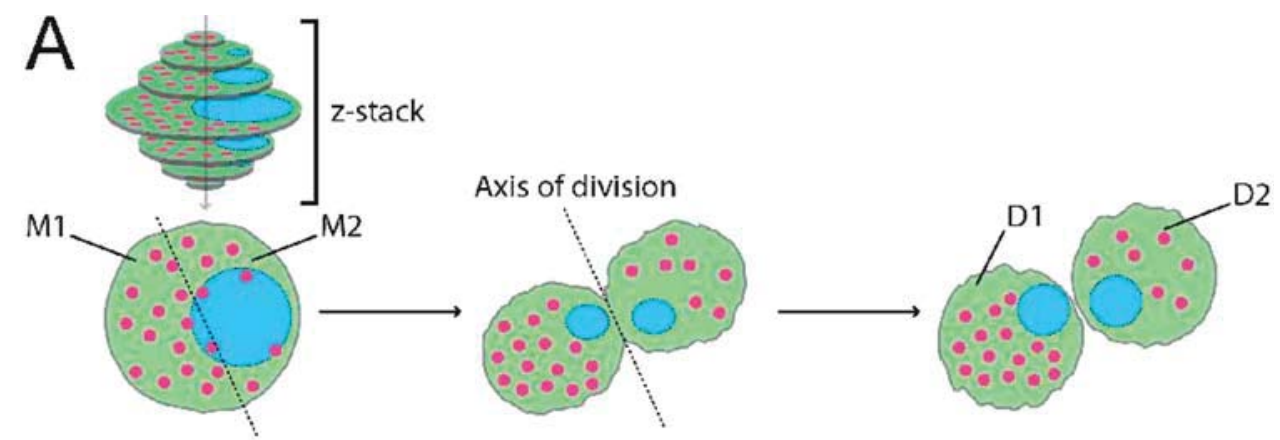

z-Projection

B
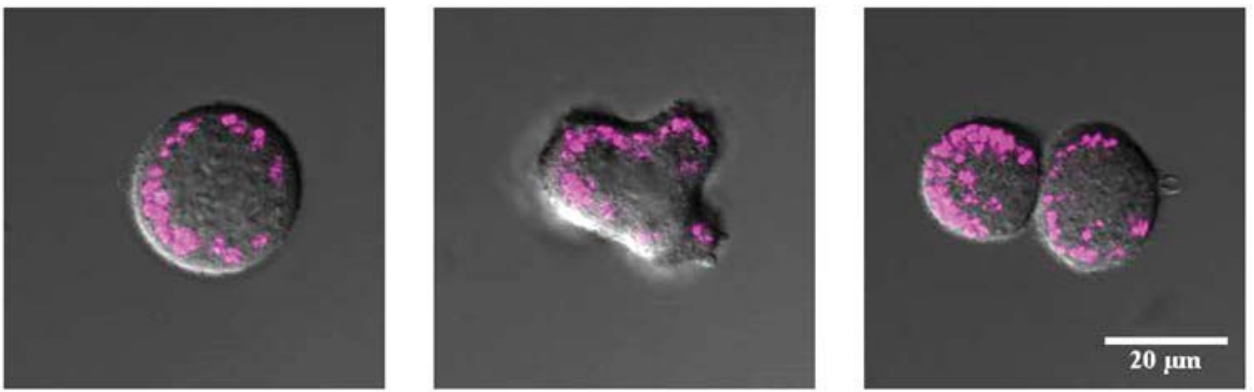

C

Differences in fluorescence signal in daughter cells

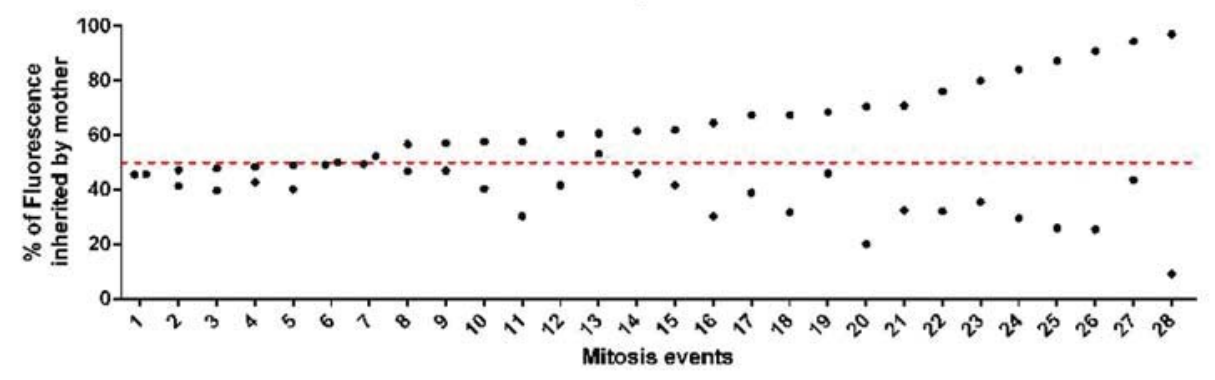

D

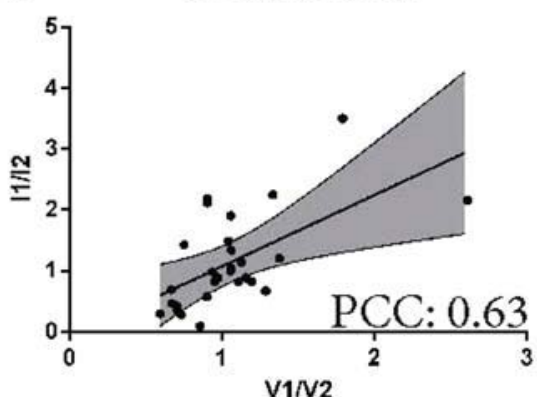

E

Intensity ratio

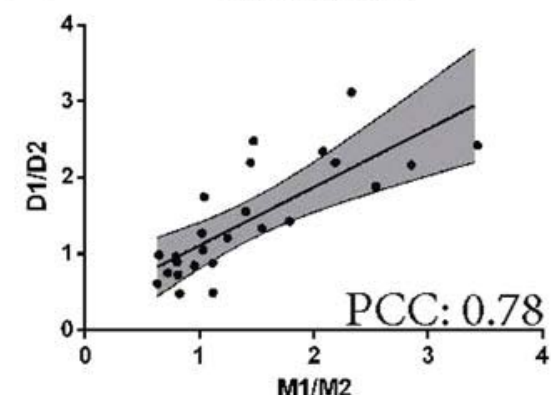

Figure 6. Cell division effectively reduces particles per cell numbers asymmetrically. (A) Schematic depiction of the analysis of mitotic events. Zstacks were first projected onto a single plane by summation of the individual images. The intensity of the NPs in the mother cell was then calculated with the area of the cell and the mean intensity over this area. The division was then observed, and the axis of division was determined during cytokinesis. The axis was overlaid on the mother to split the cell into two parts (M1 and M2). The intensity was then calculated for the daughters and compared to the two parts of the mother. (B) Representative single plane images done by live cell imaging using confocal laser microscopy before, during, and after mitosis. Scale bar $=20 \mu \mathrm{m}$. (C) Differences of the daughter cells' fluorescent signal compared to their mother's. The two dots represent the daughter cells. The $50 \%$ line (red dashed line) marks an even-split event. The events were sorted to the highest fluorescence in a daughter. The average daughter receives $51.6 \%$ of the mother's fluorescence. (D) Correlation between the daughters' volumes (V1 and V2) to their corresponding fluorescent signals (I1 and I2). Pearson's correlation coefficient (PCC) showed a positive correlation of 0.63 . The gray area represents the $99 \%$ confidence interval; the black line shows the least-squares linear fit. (E) Correlation between the mother's two-part fluorescent intensities (M1 and M2) to the corresponding daughters' fluorescent signals (D1 and D2). PCC showed a strong positive correlation coefficient of 0.78 . The gray area represents the $99 \%$ confidence interval; the black line shows the leastsquares linear fit. 
NPs is exocytosed. The highest amount of gold found in the extracellular fraction, $14 \%$ of the total gold, was seen in HeLa cells exposed to $46 \mathrm{~nm} \mathrm{Au@PVP} \mathrm{NPs.} \mathrm{This} \mathrm{observation} \mathrm{is}$ supported by the DF micrographs (see Figure 3), which showed that large amounts of NPs were still present inside the cells $48 \mathrm{~h}$ post-exposure, and further confirms the results obtained with the $\mathrm{SiO}_{2}$ NPs.

Our results clearly indicate that lysosomal exocytosis is celltype, and presumably NP size, dependent and it is not a main mechanism performed by macrophages in a detectable amount for any tested NP types or sizes. HeLa cells were able to release some of the intracellular particles into the extracellular space with slightly increased efficiency for the larger NPs.

The accumulation of biopersistent NPs must be taken into account, in particular, for professional-phagocytic cells that collect many thousands of NPs in their lifespan of several month to years. ${ }^{70}$ This NP accumulation could potentially interfere with the immune cells' natural function of clearing pathogens from the surrounding tissue and, thus, could provoke local results similar to immune deficiencies. ${ }^{71,72}$ Most prone to such effects would be the residual macrophages in organs that are readily exposed to NPs, such as the lung, liver, spleen, kidney, and gastro-intestinal tract. ${ }^{1}$ It has been shown that alveolar macrophages in smokers were filled with particles, which caused a reduction in the motility of the macrophages and the subsequent significant impairment of the early immune response against tuberculosis. ${ }^{71}$ Furthermore, chronic exposure to Au NPs can impair macropinocytosis: Au NP-laden endothelial cells showed reduced proliferation capacity and increased endoplasmic reticulum (ER) stress even when no acute toxicity was observed. $8,49,73$

Mitosis Explains the Reduction of Fluorescence over Time and Is Asymmetric. As the dilution due to cell division was the only effective mechanism-reducing cellular NP load we observed with the herein used NP and cell types, we investigated the distribution of $\mathrm{SiO}_{2}$ NPs during and after mitosis of dividing cells. Previous studies showed that NPs can be diluted by mitosis in cell cultures and that the distribution can be inhomogeneous (i.e., particles are not equally split into the daughter cells). ${ }^{26,29,74,75}$

J774A.1 cells were incubated for $24 \mathrm{~h}$ with $20 \mu \mathrm{g} \mathrm{mL}^{-1} \mathrm{SiO}_{2}$ NPs and then analyzed by live cell imaging using the cLSM. The fluorescence signals were analyzed in diving cells before and after they completed cytokinesis. The workflow is shown schematically in Figure 6A. The analysis was performed by initially transforming the $3 \mathrm{D}$ image stack into a $2 \mathrm{D}$ projection by forming the sum of each individual plane. The areas of the cells were mapped using the brightfield channel, which was used as a mask for the cell contour, yielding the summed fluorescence in each cell (mother cell and two daughter cells) and time point (that is, before and after division).

Some recent publications have discussed the importance of cell volume, cell uptake receptors on the surface, and cell cycle state to accurately represent the intracellular NP concentration and uptake rates. ${ }^{6-8}$ Kim et al. showed evidence of the influence of cell cycle state on the particle internalization. On the other hand, Panet et al. found no dependence on cell cycle state, but on the cell size. We designed our study to be independent of both parameters, i.e., cell cycle state or cell size, by applying a $24 \mathrm{~h} \mathrm{NP}$ pulse exposure prior to a thorough washing step, followed by the investigation of the intracellular fate over up to $72 \mathrm{~h}$ at the single cell level. Having a $24 \mathrm{~h}$ exposure ensures that most of the cells have undergone one complete cell cycle, and therefore, less influence of the cell cycle state at the time of exposure can be assumed. Furthermore, by following individual cells through mitosis our results are also independent of variations during the uptake, which is completed before the investigation starts.

We analyzed 28 individual mitotic events from five independent live cell imaging experiments. A representative cell division is shown in Figure $6 \mathrm{~B}$. Figure $6 \mathrm{C}$ shows the fluorescent signal distribution of the two daughter cells of all the individual mitotic events. The fluorescence signals were normalized (mother cell is $100 \%$ ), and the red dashed line shows the 50:50 distribution of the two daughter cells from the mother's initial fluorescent signal. The volume of the daughter cells (estimated from the bright field area of the cells) correlated positively with the fluorescence signal (correlation coefficient $=$ 0.63 ), implying that bigger cells tend to receive more NPs (Figure 6D).

The distribution of the NPs in the daughter cells was corrected for the angle of the cleavage furrow of the mother cell (the cell's axis of division during cytokinesis). The spatial localization of NPs in the mother cells correlated to the distribution of NPs in the daughter cells (correlation coefficient or fluorescence ratios $=0.78$, Figure $6 \mathrm{E}$ ) suggests that the position of the NPs in the mother cells is the key factor defining the destination of the NPs during mitosis. Therefore, the differences in NP distribution in the daughter cells are likely due to an inhomogeneous distribution of the NPs inside the mother cell. We observed that the cell nucleus takes up a large volume, which prevents an even distribution of the lysosomal pool throughout the cytoplasm (see Figure 2). This distribution pattern is likely due to the location of the microtubule organizing center (MTOC), which is usually located close to the nucleus as shown by others. ${ }^{76}$ This condition remained even after chromosome condensation during interphase of mitosis. During mitosis the NP-containing lysosomes are coupled to the microtubular network that brings them close to the equatorial plane, but this step does not involve an active sorting mechanism. ${ }^{77}$ This is in line with other studies which showed that the partitioning of lysosomes in mitotic cells is a stochastic process and that there is no evidence of a mechanism to ensure equal distribution of these organelles into the daughter cells. $^{78-80}$

In a recent publication, it was shown that lysosomes form clusters with higher abundancies close to the nucleus to enhance the probability to fuse with incoming late endosomes containing uptaken NPs. ${ }^{81}$ This results in a nonuniform distribution of lysosomes within the cells, supporting our observations.

Here, we show that in the case of J774A.1 the uneven distribution of $\mathrm{SiO}_{2} \mathrm{NPs}$ into the daughter cells is the result of the original location of the NLV in the mother cells. The correlation coefficient of 0.78 between the mother's NP location and the daughters' NP distributions gives a strong indication that no active sorting mechanism, for example, one to prevent the spreading of NPs to the whole population that has been speculated about, is present. ${ }^{29}$

We expect these results to be NP-type independent, as the units of distribution are vesicles not single particles. These findings are of great relevance for dividing cells since even a few mitotic events cause a high variance in NP load in the cell population. The impact of this phenomenon on NPs used for nanomedical applications such as cancer research and therapy is a topic which needs to be addressed. ${ }^{82-84}$ This can also be used in imaging techniques relying on NPs as imaging agents (e.g., SPIONs as MRI contrast agents) as the NPs may rapidly be 
diluted in the fast dividing cancer cells, whereas the NP population would remain relatively stable in the surrounding healthy tissue. ${ }^{85}$ Ultimately, the same goes for chemotherapeutic drugs attached to NPs as a delivery agent, whose efficacy drops quickly when a minimum intracellular concentration cannot be reached. ${ }^{86}$

\section{CONCLUSIONS}

Our study has shown that the model NPs tested are retained in the J774A.1 cell line and primary human macrophages. There is no detectable amount of exocytosis of the $\mathrm{SiO}_{2}$ and $\mathrm{Au}$ NPs particles at the tested sizes ( 20 and $46 \mathrm{~nm}$ for Au NPs and $70 \mathrm{~nm}$ for $\mathrm{SiO}_{2}$ ) and herein used cells, once they were located inside lysosomes even after a long period of time. Our results highlight the importance of studies that investigate the fate of NPs for longer than $24 \mathrm{~h}$. In particular, macrophages should be in focus as they are usually the first cell types coming in contact with NPs and they cannot clear biopersistent materials.

Moreover, we showed that dividing cells dilute their NP cargo effectively by cell division. The quantification of individual mitotic events showed that the distribution of $\mathrm{SiO}_{2} \mathrm{NPs}$ in J774A.1 does not always follow a symmetric pattern. We were able to correlate the distribution of the individual daughter cells to the location of the NPs in the mother cells, suggesting that the different distribution has its origin in the parental spatial distribution of the NPs rather than an active sorting process. This difference in distribution has to be taken into account when conducting experiments with dividing cells (usually cancer cell lines) since the NP load per cell might vary significantly and additional studies with nondividing cells are recommended.

\section{EXPERIMENTAL METHODS}

Synthesis of Nonporous Silica NPs. The NP synthesis was performed following a modified Stöber method previously described in literature. ${ }^{87,88}$ Shortly thereafter, tetraethyl orthosilicate (SigmaAldrich, USA) was added to a preheated mixture of ethanol, deionized water, and ammonium hydroxide in order to form $50 \mathrm{~nm}$ NPs. After 3 min of core formation, a (3-aminopropyl) triethoxysilane (APTES, Sigma-Aldrich, USA)-RhoB conjugate, prepared the previous day by mixing APTES with rhodamine B isothiocyanate in ethanol and stirring overnight, was added to the mixture to form fluorescently labeled layers around these cores. The reaction was stirred further for $5 \mathrm{~h}$ and cleaned by dialysis in deionized water for 1 week with daily exchange of water. After dialysis, the suspension was filtered over a $0.2 \mu$ m cellulose acetate filter.

The particle size was then determined by transmission electron microscopy (TEM, Tecnai G2 Spirit, Thermo Fisher Scientific Inc., USA) and calculated using a FIJI particle size analyzation script (ImageJ, National Institutes of Health; Bethesda, MD, USA). The NPs were further characterized with their hydrodynamic diameter (DLS, Brookhaven Instruments Corp., USA), their $\zeta$ potential (Brookhaven Instruments Corp., USA), and their UV-vis absorbance spectrum (Jasco Europe S. R. L., Italy). The concentration was determined by measuring the weight of $2 \mathrm{~mL}$ of particle suspension after evaporating the water at $70^{\circ} \mathrm{C}$.

Synthesis of Au NPs. The synthesis of the Au NPs was performed using the Turkevich method published elsewere. ${ }^{32}$ Briefly, $2.63 \mathrm{~mL}$ of $\mathrm{Au}^{\mathrm{III}}$ chloride trihydrate $(0.095 \mathrm{M}$, Sigma-Aldrich, USA) was dissolved in $500 \mathrm{~mL}$ of $\mathrm{MQ} \mathrm{H}_{2} \mathrm{O}$ (Merck KGaA, Germany) and brought to boil while stirring. Upon boiling, $10 \mathrm{~mL}$ of sodium citrate tribasic dehydrate (10\%, Sigma-Aldrich) was added. After several minutes, the reaction turned from black to deep red showing the termination of the reaction resulting in $14 \mathrm{~nm}$ citrate-coated Au NPs.

Larger particles were obtained by an additional particle growth reaction through the addition of hydroxylamine hydrochloride $(3 \mathrm{~mL}$ of
$0.2 \mathrm{M})$ to a solution of $\mathrm{Au}^{\mathrm{III}}$ chloride trihydrate $(0.25 \mathrm{mM}$ in $270 \mathrm{~mL}$ of $\left.\mathrm{mQH} \mathrm{H}_{2} \mathrm{O}\right)$ followed by the addition of the $14 \mathrm{~nm}$ Au NPs seed $(30 \mathrm{~mL})$.

Finally, the citrate-coated NPs were recoated using polyvinylpyrrolidone (PVP, Acros Organics) with an approximate coating density of 120 molecules per $\mathrm{nm}^{2}$. This was obtained by dissolving PVP (8000 $\mathrm{MW}$ ) in $\mathrm{mQ} \mathrm{H}_{2} \mathrm{O}$. Under constant stirring the Au NPs were slowly added dropwise to the PVP solution and allowed to stir overnight. The next day, the NPs were centrifuged for $1 \mathrm{~h}$ at $8000 \mathrm{~g}$ and the supernatant was exchanged to fresh $\mathrm{MQH}_{2} \mathrm{O}$. Then the NPs were centrifuged for 1 $\mathrm{h}$ at $1,000 \mathrm{~g}$, and the supernatant was expelled again. Finally, the NPs were dispersed in fresh $\mathrm{MQ} \mathrm{H}_{2} \mathrm{O}$ and characterized.

Cell Culture. The mouse macrophage cell line J774A.1 (ATCC) was cultivated in Roswell Park Memorial Institute 1640 (RPMI, Gibco, Life Technologies Europe B.V., Zug, Switzerland) cell culture medium supplemented with fetal bovine serum (FBS, 10\%, PAA Laboratories, Chemie Brunschwig AG, Basel, Switzerland Switzerland, Life Technologies Europe B.V., Zug, Switzerland), L-glutamine (1\%, Gibco, Life Technologies Europe B.V., Zug, Switzerland), penicillin (100 units $\mathrm{mL}^{-1}$, Gibco, Life Technologies Europe B.V., Zug, Switzerland), and streptomycin (100 $\mu \mathrm{g} \mathrm{mL}{ }^{-1}$, Gibco, Life Technologies Europe B.V., Zug, Switzerland), further noted as cRPMI. The T75 culture flaks were kept at $37{ }^{\circ} \mathrm{C}, 5 \% \mathrm{CO}_{2}$, and $95 \%$ humidity. At around $80 \%$ confluency, the RPMI was exchanged and the cells were scraped off the flask using a cell scraper. A $10-20 \%$ portion of the cell suspension was then added to a new T75 flask (TPP Techno Plastic Products AG, Switzerland) and supplemented with fresh medium. The rest of the cell suspension was further used for experiments.

The human cervix carcinoma cell line HeLa (ATCC) was cultured in Dulbecco's modified eagle media (Gibco, Life Technologies Europe B.V., Zug, Switzerland) supplemented with $10 \%$ FCS, penicillin (100 u $\mathrm{mL}^{-1}$, Gibco, Life Technologies Europe B.V., Zug, Switzerland) and streptomycin $\left(100 \mu \mathrm{g} \mathrm{mL}^{-1}\right.$, Gibco, Life Technologies Europe B.V., $\mathrm{Zug}$, Switzerland). The cell cultures were kept under sterile conditions at $37{ }^{\circ} \mathrm{C}, 5 \% \mathrm{CO}_{2}$, and $95 \%$ humidity. Prior to use, the cells were washed with fresh PBS (pH 7.2, Gibco, Life Technologies Europe B.V., $\mathrm{Zug}$, Switzerland) and further detached using a mixture of Trypsin and EDTA (T/E, 0.25\%, sterile-filtered, Gibco, Life Technologies Europe B.V., Zug, Switzerland) for $5 \mathrm{~min}$ at $37^{\circ} \mathrm{C}$.

Primary human macrophages (MDMs) were obtained by isolating and further differentiating human peripheral blood monocytes from buffy coats as previously described. ${ }^{89}$ Briefly, human blood was separated using density gradient filtration (Lymphoprep, Grogg Chemie). The monocyte fraction was extracted from the mixture and purified using $\mathrm{CD} 14^{+}$magnetic microbeads (Milteny Biotech, Germany). The isolated monocytes were then differentiated using colony stimulating factor 1 (m-CSF $1,10 \mathrm{ng} \mathrm{mL}{ }^{-1}$, Milteny Biotech, Germany) supplemented cRPMI for 1 week.

Prior to seeding, the concentration of cells in suspension was determined using the trypan blue assay and an automated cell counter (EVE, NanoEnTek Inc., South Korea). For this, the cell suspension was mixed 1:1 with trypan blue (Sigma-Aldrich, USA) and pipetted into a cell counting slide. The cells were incubated for at least $4 \mathrm{~h}$ before exposing to the NPs $\left(20 \mu \mathrm{g} \mathrm{mL}^{-1}\right)$ for $24 \mathrm{~h}$. After exposure the cells were washed three times in PBS and incubated in fresh cRPMI for up to $48 \mathrm{~h}$ post-exposure.

Cytotoxicity. Cytotoxicity assays were performed using cells grown in eight-well microscopy slides. The cells were exposed $72 \mathrm{~h}$ to various concentrations of NPs $\left(0-320 \mu \mathrm{g} \mathrm{m}^{-1}\right)$. After exposure, lactate dehydrogenase (LDH, Sigma-Aldrich, USA) and resazurin assays were performed. Briefly, Triton X-100 was added to the positive control 15 min prior to collecting the supernatant of each well. After collection, cRPMI supplemented with resazurin $\left(23 \mu \mathrm{g} \mathrm{mL}^{-1}\right)$ was added to each well for $3 \mathrm{~h}$. In the meantime, LDH levels were measured in triplicate by following the manufacturer's protocol. The absorbance (DUAL function with 490 and $630 \mathrm{~nm}$ as reference wavelengths) was recorded using a microplate reader (Bio-Rad, USA). The supernatant containing resazurin and its fluorescent metabolic product resarufin was subsequently collected, and the fluorescence (Excitation: $560 \mathrm{~nm} /$ 
Emission: $590 \mathrm{~nm}$ ) was recorded using a microplate reader. Adequate medium and water only controls were done but are not shown.

Flow Cytometry. For FC, the cells were scraped off and centrifuged at $4{ }^{\circ} \mathrm{C}$ for $5 \mathrm{~min}$ at $300 \mathrm{~g}$. The supernatant was discarded, and the cell pellet was resuspended in PBS. This wash was repeated twice for a total of three washes, but the final resuspension was in cold FC buffer (PBS supplemented with $1 \%$ bovine serum albumin (BSA, Sigma-Aldrich, USA) and $0.1 \%$ sodium azide, Sigma-Aldrich, USA). The fluorescence in cells was then measured with a BD LSR FORTESSA (BD Biosciences, USA) using the PE filter set. The threshold was set to measure 30,000 cells per sample.

Ionomycin. The cells were grown in six-well plates and then exposed to $20 \mu \mathrm{g} \mathrm{mL}^{-1}$ of $\mathrm{SiO}_{2} \mathrm{NPs}$ for $24 \mathrm{~h}$. After exposure, the cells were extensively washed three times with PBS and further incubated with fresh, NP-free culture medium supplemented with $20 \mu \mathrm{M}$ of ionomycin (Sigma-Aldrich, USA) for $6 \mathrm{~h}$ and further analyzed using FC. Control samples were treated the same but incubated without the addition of ionomycin.

Fluorescence Imaging. The cells were washed three times with PBS and fixed with $4 \%$ paraformaldehyde (PFA, Sigma-Aldrich, USA) in PBS for $10 \mathrm{~min}$ at room temperature. The cells were then washed with washing buffer (PBS supplemented with $0.1 \%$ BSA and $0.001 \%$ sodium azide) for $5 \mathrm{~min}$. The cells were permeabilized in $0.2 \%$ Triton $\mathrm{X}-100$ in PBS for $10 \mathrm{~min}$ at room temperature. Next, the samples were washed three times with washing buffer for approximately 2 min per wash. Then the cells were stained using 4',6-diamidino-2-phenylindole $\left(100 \mu \mathrm{g} \mathrm{mL}^{-1}\right.$, Sigma-Aldrich, USA) and Phalloidin Alexa Fluor 488 (1:100, Thermo Fisher Scientific Inc., USA) in PBS supplemented with $0.1 \%$ Triton X-100 (Fluka, Fisher Scientific AG, Switzerland) and 1\% BSA for $1.5 \mathrm{~h}$ at room temperature in the dark. The staining solution was discarded, and the cells were washed five times with PBS for $5 \mathrm{~min}$ each. After removal of PBS, a drop of Glycergel mounting medium (Merck KGaA, Germany) was added onto the cells and then covered with a glass coverslip. Images were then acquired using a Zeiss 710 cLSM with excitation lasers of $405 \mathrm{~nm}$ (DAPI), $488 \mathrm{~nm}$ (Alexa Fluor 488), and $561 \mathrm{~nm}$ (rhodamine B) equipped with a Plan-Apochromat $63 x / 1.4$ Oil M27 objective (Zeiss GmbH, Germany). The average NLV-size was acquired using a 3D rendering of the rhodamine B channel in Imaris (Bitplane, Oxford Instruments, Switzerland).

Darkfield Imaging. To visualize the interaction and association of the Au NPs with the cells darkfield imaging was used. Cells (40,000 cells per well) were seeded in a four-well microscopy slide. After overnight attachment, the cells were then exposed to $20 \mu \mathrm{g} \mathrm{mL}^{-1}$ of Au NPs and incubated for $24 \mathrm{~h}$. Then the cells were washed three times with PBS and fixed with 4\% PFA in PBS for $10 \mathrm{~min}$ at room temperature. The cells were washed with washing buffer (PBS supplemented with $0.1 \%$ BSA and $0.001 \%$ sodium azide) for $5 \mathrm{~min}$. The cells were permeabilized in $0.2 \%$ Triton X-100 in PBS for 10 min at room temperature. Next, the samples were washed three times with washing buffer for approximately $2 \mathrm{~min}$ per wash. Then the cells were stained using DAPI $\left(100 \mu \mathrm{g} \mathrm{mL}^{-1}\right)$ and phalloidin rhodamine $(1: 100)$ in PBS supplemented with $0.1 \%$ Triton X-100 and 1\% BSA for $1.5 \mathrm{~h}$ at room temperature in the dark. The staining solution was discarded, and the cells were washed five times with PBS for 5 min each. After removal of the PBS, a drop of glycergel mounting medium was added onto the cells and then covered with a glass coverslip. The cells were then imaged using a CytoViva hyperspectral microscope (CytoViva, Inc., USA) equipped with a Dolan-Jenner DC-950 light source, UPL Fluorite 100× objective, and SPECIM V10E imaging spectrograph with a 3D (EXi Blue) fluorescence/dark field detector. The average spot size was acquired by running the FIJI (NIH, USA) particle analysis script on the initially binarized and watershed images.

Ion-Coupled Plasma Optical Emission Spectroscopy. The cells and supernatants of different post-exposure times $(0-48 \mathrm{~h})$ were collected and evaporated overnight at $70^{\circ} \mathrm{C}$ in 48 -well plates. The dried samples were then resuspended in $500 \mu \mathrm{L}$ of a mixture of $\mathrm{H}_{2} \mathrm{O}_{2}: \mathrm{HNO}_{3}$ (2:1, Sigma-Aldrich, USA) for $3 \mathrm{~h}$ at room temperature. The plates were sonicated for $20 \mathrm{~min}$ at $50{ }^{\circ} \mathrm{C}$ to release excess $\mathrm{H}_{2} \mathrm{O}_{2} /$ gas. Afterward, $400 \mu \mathrm{L}$ of $\mathrm{HCl}(37 \%, \mathrm{VWR}, \mathrm{USA})$ was added to each well and incubated overnight in a chemical hood. After incubation, the samples were transferred into $15 \mathrm{~mL}$ Falcon tubes. Each well was washed three times with $\mathrm{mQ}_{2} \mathrm{O}$, and the washes were added to the Falcon tubes. Every tube was then filled to $10 \mathrm{~mL}$ with $\mathrm{mQ}_{2} \mathrm{O}$. The samples were further analyzed at ICP-OES (Optima 7000 DV, PerkinElmer, USA) and compared to a standard curve prepared gravimetrically using a gold standard (Sigma-Aldrich, USA).

Live Cell Imaging of Mitotic Events. J774A.1 cells were cultivated in six-well plates and exposed to $20 \mu \mathrm{g} \mathrm{mL}^{-1}$ of the RhoB$\mathrm{SiO}_{2} \mathrm{NPs}$ for $24 \mathrm{~h}$. After exposure, the cells were washed three times with fresh PBS, detached, and counted as previously described. Roughly 50,000 cells per well were seeded in a four-chamber live cell imaging slide (Nunc Lab-Tek II Chambered Coverglass, Thermo Fisher Scientific Inc., USA) and were allowed to attach for at least $1 \mathrm{~h}$. After attachment, the microscopy slide was transferred into the preheated live cell imaging chamber of a Zeiss $710 \mathrm{cLSM}$. After $1 \mathrm{~h}$ of temperature stabilization, the cells were imaged using z-stack, time lapse imaging (10 min resolution) at $63 \times$ magnification. After acquisition, the videos were checked for mitotic events which were further analyzed using the opensource software FIJI.

Analysis of Mitotic Events. Dividing cells were identified in the observation field and cropped before and after cell division. The z-stack was then transformed into a single plane image by forming the sum over the $z$-axis. The phase contrast channel was binarized and used to mask the cells. The mask was then multiplied with the previously acquired sum of the $z$-axis to obtain the total fluorescence intensity of a cell. The volume of the daughter cells was then extrapolated by transforming the area of the z-projection using $V=A^{3 / 2}$, assuming spherical cells. The axis of cell division was assessed in the image and used to split the mother cell into two parts (M1 and M2). The correlation between M1 and M2 cells was further compared to D1 and D2 cells. Correlation coefficients were calculated as

$$
\rho=\frac{\operatorname{cov}(X, Y)}{\sigma_{X} \sigma_{Y}}
$$

where cov is the covariance, $\sigma_{X}$ is the standard deviation of $X$, and $\sigma_{Y}$ is the standard deviation of $Y$.

Analysis of Colocalization of $\mathrm{SiO}_{2} \mathrm{NPs}$ and Lysosomes. The different cell lines were exposed to $20 \mu \mathrm{g} \mathrm{mL}^{-1}$ of the RhoB- $\mathrm{SiO}_{2} \mathrm{NPs}$ for $24 \mathrm{~h}$. After exposure, the cells were washed three times with PBS and further incubated with fresh cCCM supplemented with $75 \mathrm{nM}$ LysoTracker Green DND-26 (Invitrogen, Thermo Fisher Scientific Inc., USA) for $15 \mathrm{~min}$. Afterward, the cells were immediately imaged in a live cell setting described above. The colocalization was calculated using the imaging analysis software Imaris.

Fluorescence Stability of Rhodamine B Labeled $\mathrm{SiO}_{2}$ NPs. The potential quenching of fluorescence in the lysosomal milieu was tested by incubating the NPs in artificial lysosomal fluid. Sodium chloride $(3.210 \mathrm{~g})$, sodium hydroxide $(6.000 \mathrm{~g})$, citric acid $(20.800 \mathrm{~g})$, calcium chloride $(0.097 \mathrm{~g})$, sodium phosphate heptahydrate $(0.179 \mathrm{~g})$, sodium sulfate $(0.039 \mathrm{~g})$, magnesium chloride hexahydrate $(0.106 \mathrm{~g})$, glycerin $(0.059 \mathrm{~g})$, sodium citrate dihydrate $(0.077 \mathrm{~g})$, sodium tartrate dihydrate $(0.090 \mathrm{~g})$, sodium lactate $(0.085 \mathrm{~g})$, sodium pyruvate $(0.086$ $\mathrm{g}$ ), and formaldehyde $(1.000 \mathrm{~mL})$ (added fresh before use) were dissolved in a total of $200 \mathrm{~mL}$ of MiliQ water forming a $5 \times$ stock solution. The stock solution was further diluted with MQ water and NP suspension in order to obtain a $1 \times$ ALF solution containing $1 \mathrm{mg} \mathrm{mL}^{-1}$ of $\mathrm{SiO}_{2} \mathrm{NPs}$. The fluorescence of $100 \mu \mathrm{L}$ of this solution was measured after $0,1,2,3$, and 30 days of incubation at $37^{\circ} \mathrm{C}$ and $5 \% \mathrm{CO}_{2}$ using a microplate plate reader (Bio-Rad, USA). Incubation of the NPs in PBS was used as a control. The experiment was measured in triplicate.

CryoTEM. Lacey cryoTEM grids (Agar scientific, UK) were glow discharged for $20 \mathrm{~s}$ at $10 \mathrm{~W}$ in air using a plasma cleaner (Diener, Germany). Five microliters of $\mathrm{SiO}_{2} \mathrm{NP}$ solution $(\sim 250 \mu \mathrm{g} / \mathrm{mL}$, in cRPMI for $24 \mathrm{~h}$ ) was pipetted onto the cleaned grid side and mounted on a home-built guillotine cryoplunger using inverted tweezers. The grids were blotted (5 s) with filter paper (Whatman, grade 40) and immediately plunged in an eutectic mixture of ethane and propane cooled to $77 \mathrm{~K}$ by liquid nitrogen. The sample was transferred onto a 626 single tilt liquid nitrogen cryo-transfer holder (Gatan, CA, USA) 
and observed in a ThermoFischer Spirit transmission electron microscope (ThermoFischer, MA, USA) equipped with a LaB6 filament at $120 \mathrm{kV}$. The images were recorded using a bottom-mount 4K Eagle camera (ThermoFischer, MA, USA) using a low dose mode of SerialEM.

$\boldsymbol{\beta}$-Hexosaminidase Assay. A total of 300,000 MDM cells per well were seeded in a 12 -well plate and left attached overnight. The cells were then exposed to cCCM supplemented with ionomycin $(20 \mu \mathrm{M})$. After $6 \mathrm{~h}$ of exposure, the supernatant was collected and the cells were lysed by adding fresh cell culture media supplemented with $0.1 \%$ Triton X-100 for $15 \mathrm{~min}$. A $75 \mu \mathrm{L}$ portion of the supernatant or lysate was then mixed with $50 \mu \mathrm{L}$ of substrate solution (5.84 mM 4-nitrophenyl $\mathrm{N}$ acetyl- $\beta$-D-galactosaminide in citrate buffer, $\mathrm{pH} 4.5$ ) and incubated in a 96-well plate for $1 \mathrm{~h}$ at $37^{\circ} \mathrm{C}$. The turnover was subsequently stopped using $100 \mu \mathrm{L}$ of borate buffer $\left(0.2 \mathrm{M}\right.$ boric acid in $\left.\mathrm{MQ}_{2} \mathrm{O}, \mathrm{pH} 10\right)$, and the absorbance at $405 \mathrm{~nm}$ was assessed using a plate reader. The supernatant value was further compared with the values from the cell lysate + supernatant values, while cCCM + substrate solution was used as background value.

\section{ASSOCIATED CONTENT}

\section{Supporting Information}

The Supporting Information is available

NP stability tests in cRPMI, cytotoxicity results of the different particles, colocalization of $\mathrm{SiO}_{2} \mathrm{NP}$ and lysosomes, spot size analysis of DF micrographs, stability of $\mathrm{SiO}_{2} \mathrm{NPs}$ ' fluorescence in $\mathrm{ALF}$, release of $\beta$ hexosaminidase upon ionomycin incubation in MDMs, fluorescence development in proliferation inhibited cells, and Rscript for proliferation simulations(PDF)

\section{AUTHOR INFORMATION}

\section{Corresponding Author}

*E-mail: barbara.rothen@unifr.ch.

\section{ORCID}

Joël Bourquin: 0000-0001-8345-710X

Dedy Septiadi: 0000-0003-2353-7508

Sandor Balog: 0000-0002-4847-9845

Lukas Steinmetz: 0000-0003-4255-2738

Miguel Spuch-Calvar: 0000-0002-6679-2624

Patricia Taladriz-Blanco: 0000-0002-2469-9704

Alke Petri-Fink: 0000-0003-3952-7849

Barbara Rothen-Rutishauser: 0000-0002-7805-9366

\section{Funding}

We acknowledge the Swiss National Science Foundation (310030_159847/1) and the Adolphe Merkle Foundation for financial support.

\section{Notes}

The authors declare no competing financial interest.

\section{ACKNOWLEDGMENTS}

We kindly thank Hana Barosova, Roman Lehner, Barbara Drasler, and Christoph Bisig for their help in isolating monocytes from human blood donations. Furthermore, we thank Jessica Caldwell for proofreading and improving the language of the manuscript.

\section{REFERENCES}

(1) Bourquin, J.; Milosevic, A.; Hauser, D.; Lehner, R.; Blank, F.; PetriFink, A.; Rothen-Rutishauser, B. Biodistribution, Clearance, and LongTerm Fate of Clinically Relevant Nanomaterials. Adv. Mater. 2018, 30, 1704307.
(2) Bobo, D.; Robinson, K. J.; Islam, J.; Thurecht, K. J.; Corrie, S. R. Nanoparticle-Based Medicines: A Review of FDA-Approved Materials and Clinical Trials to Date. Pharm. Res. 2016, 33, 2373-2387.

(3) Cho, M.; Cho, W.-S.; Choi, M.; Kim, S. J.; Han, B. S.; Kim, S. H.; Kim, H. O.; Sheen, Y. Y.; Jeong, J. The Impact of Size on Tissue Distribution and Elimination by Single Intravenous Injection of Silica Nanoparticles. Toxicol. Lett. 2009, 189, 177-183.

(4) Alexis, F.; Pridgen, E.; Molnar, L. K.; Farokhzad, O. C. Factors Affecting the Clearance and Biodistribution of Polymeric Nanoparticles. Mol. Pharmaceutics 2008, 5, 505-515.

(5) van Furth, R. Mononuclear Phagocyte System. In Encyclopedia of Immunology; Elsevier, 1998; pp 1755-1758.

(6) Huotari, J.; Helenius, A. Endosome Maturation. EMBO J. 2011, 30, 3481-3500.

(7) Hu, Y.-B.; Dammer, E. B.; Ren, R.-J.; Wang, G. The EndosomalLysosomal System: From Acidification and Cargo Sorting to Neurodegeneration. Transl. Neurodegener. 2015, 4, 18.

(8) Holtzman, E. Lysosomes; Springer US: Boston, MA, 1989.

(9) Xu, H.; Ren, D. Lysosomal Physiology. Annu. Rev. Physiol. 2015, $77,57-80$.

(10) Kinnear, C.; Moore, T. L.; Rodriguez-Lorenzo, L.; RothenRutishauser, B.; Petri-Fink, A. Form Follows Function: Nanoparticle Shape and Its Implications for Nanomedicine. Chem. Rev. 2017, 117, 11476-11521.

(11) Oh, N.; Park, J.-H. Endocytosis and Exocytosis of Nanoparticles in Mammalian Cells. Int. J. Nanomedicine 2014, 9 (Suppl 1), 51-63.

(12) Kou, L.; Sun, J.; Zhai, Y.; He, Z. The Endocytosis and Intracellular Fate of Nanomedicines: Implication for Rational Design. Asian J. Pharm. Sci. 2013, 8, 1-8.

(13) Gustafson, H. H.; Holt-Casper, D.; Grainger, D. W.; Ghandehari, H. Nanoparticle Uptake: The Phagocyte Problem. Nano Today 2015, $10,487-510$

(14) Sadauskas, E.; Danscher, G.; Stoltenberg, M.; Vogel, U.; Larsen, A.; Wallin, H. Protracted Elimination of Gold Nanoparticles from Mouse Liver. Nanomedicine 2009, 5, 162-169.

(15) Takenaka, S.; Karg, E.; Kreyling, W. G.; Lentner, B.; Möller, W.; Behnke-Semmler, M.; Jennen, L.; Walch, a.; Michalke, B.; Schramel, P.; Heyder, J.; Schulz, H. Distribution Pattern of Inhaled Ultrafine Gold Particles in the Rat Lung. Inhalation Toxicol. 2006, 18, 733-740.

(16) Cho, W. S.; Cho, M.; Jeong, J.; Choi, M.; Cho, H. Y.; Han, B. S.; Kim, S. H.; Kim, H. O.; Lim, Y. T.; Chung, B. H.; Jeong, J. Acute Toxicity and Pharmacokinetics of $13 \mathrm{Nm}$-Sized PEG-Coated Gold Nanoparticles. Toxicol. Appl. Pharmacol. 2009, 236, 16-24.

(17) Von Maltzahn, G.; Park, J. H.; Agrawal, A.; Bandaru, N. K.; Das, S. K.; Sailor, M. J.; Bhatia, S. N. Computationally Guided Photothermal Tumor Therapy Using Long-Circulating Gold Nanorod Antennas. Cancer Res. 2009, 69, 3892-3900.

(18) Yanes, R. E.; Tarn, D.; Hwang, A. A.; Ferris, D. P.; Sherman, S. P.; Thomas, C. R.; Lu, J.; Pyle, A. D.; Zink, J. I.; Tamanoi, F. Involvement of Lysosomal Exocytosis in the Excretion of Mesoporous Silica Nanoparticles and Enhancement of the Drug Delivery Effect by Exocytosis Inhibition. Small 2013, 9, 697-704.

(19) Andrews, N. W. Regulated Secretion of Conventional Lysosomes. Trends Cell Biol. 2000, 10, 316-321.

(20) Blott, E. J.; Griffiths, G. M. Secretory Lysosomes. Nat. Rev. Mol. Cell Biol. 2002, 3, 122-131.

(21) Czibener, C.; Sherer, N. M.; Becker, S. M.; Pypaert, M.; Hui, E.; Chapman, E. R.; Mothes, W.; Andrews, N. W. Ca2+ and Synaptotagmin VII-Dependent Delivery of Lysosomal Membrane to Nascent Phagosomes. J. Cell Biol. 2006, 174, 997-1007.

(22) Medina, D. L.; Fraldi, A.; Bouche, V.; Annunziata, F.; Mansueto, G.; Spampanato, C.; Puri, C.; Pignata, A.; Martina, J. A.; Sardiello, M.; Palmieri, M.; Polishchuk, R.; Puertollano, R.; Ballabio, A. Transcriptional Activation of Lysosomal Exocytosis Promotes Cellular Clearance. Dev. Cell 2011, 21, 421-430.

(23) Chithrani, B. D.; Chan, W. C. W. Elucidating the Mechanism of Cellular Uptake and Removal of Protein-Coated Gold Nanoparticles of Different Sizes and Shapes. Nano Lett. 2007, 7, 1542-1550. 
(24) Oh, N.; Park, J.-H. Surface Chemistry of Gold Nanoparticles Mediates Their Exocytosis in Macrophages. ACS Nano 2014, 8, 62326241.

(25) Kim, J. A.; Åberg, C.; Salvati, A.; Dawson, K. A. Role of Cell Cycle on the Cellular Uptake and Dilution of Nanoparticles in a Cell Population. Nat. Nanotechnol. 2012, 7, 62-68.

(26) Summers, H. D.; Brown, M. R.; Holton, M. D.; Tonkin, J. A.; Hondow, N.; Brown, A. P.; Brydson, R.; Rees, P. Quantification of Nanoparticle Dose and Vesicular Inheritance in Proliferating Cells. ACS Nano 2013, 7, 6129-6137.

(27) Summers, H. D.; Rees, P.; Holton, M. D.; Brown, M. R.; Chappell, S. C.; Smith, P. J.; Errington, R. J. Statistical Analysis of Nanoparticle Dosing in a Dynamic Cellular System. Nat. Nanotechnol. 2011, 6, 170-174.

(28) Jongsma, M. L. M.; Berlin, I.; Neefjes, J. On the Move: Organelle Dynamics during Mitosis. Trends Cell Biol. 2015, 25, 112-124.

(29) Summers, H. Can Cells Reduce Nanoparticle Toxicity? Nano Today 2010, 5, 83-84.

(30) Chithrani, B. D.; Stewart, J.; Allen, C.; Jaffray, D. A. Intracellular Uptake, Transport, and Processing of Nanostructures in Cancer Cells. Nanomedicine 2009, 5, 118-127.

(31) Oh, E.; Delehanty, J. B.; Sapsford, K. E.; Susumu, K.; Goswami, R.; Blanco-Canosa, J. B.; Dawson, P. E.; Granek, J.; Shoff, M.; Zhang, Q.; Goering, P. L.; Huston, A.; Medintz, I. L. Cellular Uptake and Fate of PEGylated Gold Nanoparticles Is Dependent on Both CellPenetration Peptides and Particle Size. ACS Nano 2011, 5, 6434-6448.

(32) Turkevich, J. Colloidal Gold. Part I. Gold Bull. 1985, 18, 125131.

(33) Dragoni, S.; Franco, G.; Regoli, M.; Bracciali, M.; Morandi, V.; Sgaragli, G.; Bertelli, E.; Valoti, M. Gold Nanoparticles Uptake and Cytotoxicity Assessed on Rat Liver Precision-Cut Slices. Toxicol. Sci. 2012, 128, 186-197.

(34) Park, J. H.; Gu, L.; Von Maltzahn, G.; Ruoslahti, E.; Bhatia, S. N.; Sailor, M. J. Biodegradable Luminescent Porous Silicon Nanoparticles for in Vivo Applications. Nat. Mater. 2009, 8, 331-336.

(35) Vivero-Escoto, J. L.; Huxford-Phillips, R. C.; Lin, W. Silica-Based Nanoprobes for Biomedical Imaging and Theranostic Applications. Chem. Soc. Rev. 2012, 41, 2673-2685.

(36) Bharti, C.; Gulati, N.; Nagaich, U.; Pal, A. Mesoporous Silica Nanoparticles in Target Drug Delivery System: A Review. Int. J. Pharm. Investig. 2015, 5, 124.

(37) Wang, T.; Zhang, L.; Su, Z.; Wang, C.; Liao, Y.; Fu, Q. Multifunctional Hollow Mesoporous Silica Nanocages for Cancer Cell Detection and the Combined Chemotherapy and Photodynamic Therapy. ACS Appl. Mater. Interfaces 2011, 3, 2479-2486.

(38) Croissant, J. G.; Fatieiev, Y.; Khashab, N. M. Degradability and Clearance of Silicon, Organosilica, Silsesquioxane, Silica Mixed Oxide, and Mesoporous Silica Nanoparticles. Adv. Mater. 2017, 29, 1604634.

(39) Shen, D.; Yang, J.; Li, X.; Zhou, L.; Zhang, R.; Li, W.; Chen, L.; Wang, R.; Zhang, F.; Zhao, D. Biphase Stratification Approach to Three-Dimensional Dendritic Biodegradable Mesoporous Silica Nanospheres. Nano Lett. 2014, 14, 923-932.

(40) Yamada, H.; Urata, C.; Aoyama, Y.; Osada, S.; Yamauchi, Y.; Kuroda, K. Preparation of Colloidal Mesoporous Silica Nanoparticles with Different Diameters and Their Unique Degradation Behavior in Static Aqueous Systems. Chem. Mater. 2012, 24, 1462-1471.

(41) Milosevic, A.; Bourquin, J.; Burnand, D.; Lemal, P.; Crippa, F.; Monnier, C. A.; Rodriguez-Lorenzo, L.; Petri-Fink, A.; RothenRutishauser, B. Artificial Lysosomal Platform to Study Nanoparticle Long-Term Stability. Chimia 2019, 73, 55-58.

(42) Meder, F.; Thomas, S. S.; Fitzpatrick, L. W.; Alahmari, A.; Wang, S.; Beirne, J. G.; Vaz, G.; Redmond, G.; Dawson, K. A. Labeling the Structural Integrity of Nanoparticles for Advanced in Situ Tracking in Bionanotechnology. ACS Nano 2016, 10, 4660-4671.

(43) Soenen, S. J.; Manshian, B.; Doak, S. H.; De Smedt, S. C.; Braeckmans, K. Fluorescent Non-Porous Silica Nanoparticles for LongTerm Cell Monitoring: Cytotoxicity and Particle Functionality. Acta Biomater. 2013, 9, 9183-9193.
(44) Bae, Y. M.; Park, Y., II; Nam, S. H.; Kim, J. H.; Lee, K.; Kim, H. M.; Yoo, B.; Choi, J. S.; Lee, K. T.; Hyeon, T.; Suh, Y. D. Endocytosis, Intracellular Transport, and Exocytosis of Lanthanide-Doped Upconverting Nanoparticles in Single Living Cells. Biomaterials 2012, 33, 9080-9086.

(45) Bartczak, D.; Nitti, S.; Millar, T. M.; Kanaras, A. G. Exocytosis of Peptide Functionalized Gold Nanoparticles in Endothelial Cells. Nanoscale 2012, 4, 4470.

(46) Chu, Z.; Huang, Y.; Tao, Q.; Li, Q. Cellular Uptake, Evolution, and Excretion of Silica Nanoparticles in Human Cells. Nanoscale 2011, 3, 3291 .

(47) Dombu, C. Y.; Kroubi, M.; Zibouche, R.; Matran, R.; Betbeder, D. Characterization of Endocytosis and Exocytosis of Cationic Nanoparticles in Airway Epithelium Cells. Nanotechnology 2010, 21, 355102 .

(48) Fiorentino, I.; Gualtieri, R.; Barbato, V.; Mollo, V.; Braun, S.; Angrisani, A.; Turano, M.; Furia, M.; Netti, P. A.; Guarnieri, D.; Fusco, S.; Talevi, R. Energy Independent Uptake and Release of Polystyrene Nanoparticles in Primary Mammalian Cell Cultures. Exp. Cell Res. 2015, 330, 240-247.

(49) Gunduz, N.; Ceylan, H.; Guler, M. O.; Tekinay, A. B. Intracellular Accumulation of Gold Nanoparticles Leads to Inhibition of Macropinocytosis to Reduce the Endoplasmic Reticulum Stress. Sci. Rep. 2017, 7, 40493.

(50) Jiang, X.; Röcker, C.; Hafner, M.; Brandholt, S.; Dörlich, R. M.; Nienhaus, G. U.; Rocker, C.; Dorlich, R. M.; Röcker, C.; Dörlich, R. M.; Hafner, M.; Brandholt, S.; Dörlich, R. M.; Nienhaus, G. U. Endo- and Exocytosis of Zwitterionic Quantum Dot Nanoparticles by Live HeLa Cells. ACS Nano 2010, 4, 6787-6797.

(51) Jin, H.; Heller, D. a; Sharma, R.; Strano, M. S. Size-Dependent Cellular Uptake and Expulsion of Single-Walled Carbon Nanotubes: Single Particle Tracking and a Generic Uptake Model for Nanoparticles. ACS Nano 2009, 3, 149-158.

(52) Slowing, I. I.; Vivero-Escoto, J. L.; Zhao, Y.; Kandel, K.; Peeraphatdit, C.; Trewyn, B. G.; Lin, V. S. Y. Exocytosis of Mesoporous Silica Nanoparticles from Mammalian Cells: From Asymmetric Cell-toCell Transfer to Protein Harvesting. Small 2011, 7, 1526-1532.

(53) Strobel, C.; Oehring, H.; Herrmann, R.; Förster, M.; Reller, A.; Hilger, I. Fate of Cerium Dioxide Nanoparticles in Endothelial Cells: Exocytosis. J. Nanopart. Res. 2015, 17, 206.

(54) Oh, Y. K.; Swanson, J. A. Different Fates of Phagocytosed Particles after Delivery into Macrophage Lysosomes. J. Cell Biol. 1996, $132,585-593$.

(55) de Chastellier, C.; Thilo, L. Phagosome Maturation and Fusion with Lysosomes in Relation to Surface Property and Size of the Phagocytic Particle. Eur. J. Cell Biol. 1997, 74, 49-62.

(56) Wang, Y.; Wu, Q.; Sui, K.; Chen, X.-X.; Fang, J.; Hu, X.; Wu, M.; Liu, Y. A Quantitative Study of Exocytosis of Titanium Dioxide Nanoparticles from Neural Stem Cells. Nanoscale 2013, 5, 4737.

(57) Hmama, Z. Quantitative Analysis of Phagolysosome Fusion in Intact Cells: Inhibition by Mycobacterial Lipoarabinomannan and Rescue by an 1, 25-Dihydroxyvitamin D3-Phosphoinositide 3-Kinase Pathway. J. Cell Sci. 2004, 117, 2131-2140.

(58) Kuhn, D. A.; Vanhecke, D.; Michen, B.; Blank, F.; Gehr, P.; PetriFink, A.; Rothen-Rutishauser, B. Different Endocytotic Uptake Mechanisms for Nanoparticles in Epithelial Cells and Macrophages. Beilstein J. Nanotechnol. 2014, 5, 1625-1636.

(59) Day, G. A.; Hoover, M. D.; Stefaniak, A. B.; Dickerson, R. M.; Peterson, E. J.; Esmen, N. A.; Scripsick, R. C. Bioavailability of Beryllium Oxide Particles: An in Vitro Study in the Murine J774A.1 Macrophage Cell Line Model. Exp. Lung Res. 2005, 31, 341-360.

(60) Schwiertz, J.; Wiehe, A.; Gräfe, S.; Gitter, B.; Epple, M. Calcium Phosphate Nanoparticles as Efficient Carriers for Photodynamic Therapy against Cells and Bacteria. Biomaterials 2009, 30, 3324-3331.

(61) Asem, H.; Zhao, Y.; Ye, F.; Barrefelt, Å.; Abedi-Valugerdi, M.; ElSayed, R.; El-Serafi, I.; Abu-Salah, K. M.; Hamm, J.; Muhammed, M.; Hassan, M. Biodistribution of Biodegradable Polymeric Nano-Carriers Loaded with Busulphan and Designed for Multimodal Imaging. J. Nanobiotechnology 2016, 14, 82. 
(62) Sakhtianchi, R.; Minchin, R. F.; Lee, K.-B. B.; Alkilany, A. M.; Serpooshan, V.; Mahmoudi, M. Exocytosis of Nanoparticles from Cells: Role in Cellular Retention and Toxicity. Adv. Colloid Interface Sci. 2013, 201-202, 18-29.

(63) Milosevic, A. M.; Rodriguez-Lorenzo, L.; Balog, S.; Monnier, C. A.; Petri-Fink, A.; Rothen-Rutishauser, B. Assessing the Stability of Fluorescently Encoded Nanoparticles in Lysosomes by Using Complementary Methods. Angew. Chem., Int. Ed. 2017, 56, 1338213386.

(64) Rodríguez, A.; Webster, P.; Ortego, J.; Andrews, N. W. Lysosomes Behave as Ca 2+-Regulated Exocytic Vesicles in Fibroblasts and Epithelial Cells. J. Cell Biol. 1997, 137, 93-104.

(65) Gray, M.; Botelho, R. J. Phagocytosis: Hungry, Hungry Cells; Humana Press, New York, NY, 2017; pp 1-16.

(66) Kadiu, I.; Nowacek, A.; McMillan, J.; Gendelman, H. E. Macrophage Endocytic Trafficking of Antiretroviral Nanoparticles. Nanomedicine 2011, 6, 975-994.

(67) Åberg, C.; Varela, J. A.; Fitzpatrick, L. W.; Dawson, K. A. Spatial and Structural Metrics for Living Cells Inspired by Statistical Mechanics. Sci. Rep. 2016, 6, 1-8.

(68) Luciani, N.; Wilhelm, C.; Gazeau, F. The Role of Cell-Released Microvesicles in the Intercellular Transfer of Magnetic Nanoparticles in the Monocyte/Macrophage System. Biomaterials 2010, 31, 70617069.

(69) Eagle, H.; Levine, E. M. Growth Regulatory Effects of Cellular Interaction. Nature 1967, 213, 1102-1106.

(70) Furth, R. The Origin and Kinetics of Mononuclear Phagocytes. Ann. N. Y. Acad. Sci. 1976, 278, 161-175.

(71) Berg, R. D.; Levitte, S.; O’Sullivan, M. P.; O’Leary, S. M.; Cambier, C. J.; Cameron, J.; Takaki, K. K.; Moens, C. B.; Tobin, D. M.; Keane, J.; Ramakrishnan, L. Lysosomal Disorders Drive Susceptibility to Tuberculosis by Compromising Macrophage Migration. Cell 2016, $165,139-152$

(72) Wu, H.-Y.; Chung, M.-C.; Wang, C.-C.; Huang, C.-H.; Liang, H.J.; Jan, T.-R. Iron Oxide Nanoparticles Suppress the Production of IL1 beta via the Secretory Lysosomal Pathway in Murine Microglial Cells. Part. Fibre Toxicol. 2013, 10, 46.

(73) Schütz, I.; Lopez-Hernandez, T.; Gao, Q.; Puchkov, D.; JaBerlinbs, S.; Nordmeyer, D.; Schmudde, M.; Rühl, E.; Graf, C. M.; Haucke, V.; Jabs, S.; Nordmeyer, D.; Schmudde, M.; Rühl, E.; Graf, C. M.; Haucke, V. Lysosomal Dysfunction Caused by Cellular Accumulation of Silica Nanoparticles. J. Biol. Chem. 2016, 291, 14170-14184.

(74) Ha, S.-W.; Camalier, C. E.; Weitzmann, M. N.; Beck, G. R.; Lee, J.-K. Long-Term Monitoring of the Physicochemical Properties of Silica-Based Nanoparticles on the Rate of Endocytosis and Exocytosis and Consequences of Cell Division. Soft Mater. 2013, 11, 195-203.

(75) Liu, K. K.; Wang, C. C.; Cheng, C. L.; Chao, J. I. Endocytic Carboxylated Nanodiamond for the Labeling and Tracking of Cell Division and Differentiation in Cancer and Stem Cells. Biomaterials 2009, 30, 4249-4259.

(76) Ruan, G.; Agrawal, A.; Marcus, A. I.; Nie, S. Imaging and Tracking of Tat Peptide-Conjugated Quantum Dots in Living Cells: New Insights into Nanoparticle Uptake, Intracellular Transport, and Vesicle Shedding. J. Am. Chem. Soc. 2007, 129, 14759-14766.

(77) Symens, N.; Soenen, S. J.; Rejman, J.; Braeckmans, K.; De Smedt, S. C.; Remaut, K. Intracellular Partitioning of Cell Organelles and Extraneous Nanoparticles during Mitosis. Adv. Drug Delivery Rev. 2012, 64, 78-94.

(78) Bergeland, T.; Widerberg, J.; Bakke, O.; Nordeng, T. W. Mitotic Partitioning of Endosomes and Lysosomes. Curr. Biol. 2001, 11, 644651.

(79) Dunster, K.; Toh, B. H.; Sentry, J. W. Early Endosomes, Late Endosomes, and Lysosomes Display Distinct Partitioning Strategies of Inheritance with Similarities to Golgi-Derived Membranes. Eur. J. Cell Biol. 2002, 81, 117-124.

(80) Errington, R. J.; Brown, M. R.; Silvestre, O. F.; Njoh, K. L.; Chappell, S. C.; Khan, I. A.; Rees, P.; Wilks, S. P.; Smith, P. J.; Summers,
H. D. Single Cell Nanoparticle Tracking to Model Cell Cycle Dynamics and Compartmental Inheritance. Cell Cycle 2010, 9, 121-130.

(81) Ba, Q.; Raghavan, G.; Kiselyov, K.; Yang, G. Whole-Cell Scale Dynamic Organization of Lysosomes Revealed by Spatial Statistical Analysis. Cell Rep. 2018, 23, 3591-3606.

(82) Nie, S. Understanding and Overcoming Major Barriers in Cancer Nanomedicine. Nanomedicine (London, U. K.) 2010, 5, 523-528.

(83) Yang, Y.; Yu, C. Advances in Silica Based Nanoparticles for Targeted Cancer Therapy. Nanomedicine 2016, 12, 317-332.

(84) Sweeney, S. K.; Luo, Y.; O'Donnell, M. A.; Assouline, J. Nanotechnology and Cancer: Improving Real-Time Monitoring and Staging of Bladder Cancer with Multimodal Mesoporous Silica Nanoparticles. Cancer Nanotechnol. 2016, 7, 3.

(85) Walczak, P.; Kedziorek, D. A.; Gilad, A. A.; Barnett, B. P.; Bulte, J. W. M. Applicability and Limitations of MR Tracking of Neural Stem Cells with Asymmetric Cell Division and Rapid Turnover: The Case of the Shiverer Dysmyelinated Mouse Brain. Magn. Reson. Med. 2007, 58, 261-269.

(86) Fan, L.; Zhang, Y.; Wang, F.; Yang, Q.; Tan, J.; Renata, G.; Wu, H.; Song, C.; Jin, B. Multifunctional All-in-One Drug Delivery Systems for Tumor Targeting and Sequential Release of Three Different AntiTumor Drugs. Biomaterials 2016, 76, 399-407.

(87) Stöber, W.; Fink, A.; Bohn, E. Controlled Growth of Monodisperse Silica Spheres in the Micron Size Range. J. Colloid Interface Sci. 1968, 26, 62-69.

(88) Larson, D. R.; Ow, H.; Vishwasrao, H. D.; Heikal, A. a; Wiesner, U.; Webb, W. W. Silica Nanoparticle Architecture Determines Radiative Properties of Encapsulated Fluorophores Silica Nanoparticle Architecture Determines Radiative Properties of Encapsulated Fluorophores. Chem. Mater. 2008, 20 (8), 2677-2684.

(89) Rothen-Rutishauser, B.; Clift, M.; Brandenberger, C.; Lehmann, A.; Müller, L.; Raemy, D.; Gehr, P. An in Vitro Model of the Human Epithelial Airway Barrier to Study the Toxicity of Nanoparticles. Toxicol. Lett. 2009, 189, S35-S36. 